\title{
Democracia y Derechos Humanos en la política exterior del Presidente Reagan*
}

Una de las críticas más severas realizadas por el candidato Ronald Reagan al Presidente Carter fue hecha a su política de derechos humanos. El triunfo de la "revolución neo-conservadora" en 1980 fue interpretado por muchos como el ocaso del interés de la política exterior estadounidense por los derechos humanos. Sin embargo, el tema ha persistido como una preocupación de la acción internacional norteamericana. Esta situación ha sido el resultado de la valoración de este componente ético-político como elemento del discurso ideológico ampliamente aceptado entre las fuerzas políticas norteamericanas y de su institucionalización en el campo de la formulación de la política exterior.

Por ello, la búsqueda de la supresión de la política de derechos humanos intentada durante los primeros meses de la Administración Reagan dio paso, más bien, a una reformulación de la política, que la rearticuló con otros fines de la acción exterior del gobierno estadounjidense. En un periodo relativamente breve, la dimensión de derechos humanos adquirió nuevamente un lugar en la formulación de la política exterior norteamericana.

Este cambio expresa la influencia de factores políticos internos en la formulación de la política exterior de los Estados Unidos, en particular la legitimidad del tema dentro del universo de valores comúnmente aceptados en la arena política estadounidense y refleja la capacidad de influencia de los grupos de derechos humanos, ejercida principalmente a través de la opinión pública y en su acción ante el Gongreso.

Con todo, el hecho de que el tema de los derechos humanos haya reaparecido en la formulación pública no significa que tenga

* Una versión perliminar de este trabajo fue presentada en el Primer Congreso de la Asociación Chilena de Ciencia Polftica realizado en Santiago el 27 y 28 de abril de 1987.

Este artículo fue publicado en la Revista Chilena de Derechos Humanos, No 7, 1987, editada por el Programa de Derechos Humanos de la Academia de Humanismo Cristiano, Santiago, Chile. 
el mismo significado que durante el periodo anterior. Para comprender la nueva política, en primer lugar se debe analizar cuidadosamente su formulación, y en seguida se deben considerar las diversas formas de aplicación de ésa política a las situaciones nacionales, en el contexto de los propósitos geopolíticos e ideológicos de la administración Reagan frente a cada uno de esos estados.

Este trabajo se centra precisamente en cómo la política exterior de Estados Unidos durante la administración Reagan ha integrado la preocupación por los derechos humanos y los objetivos de promoción de la democracia en el contexto de sus objetivos más ampl.oj de polftica exterior. Más precisamente, estudia el discurso de los formuladores de la política exterior norteamericana; la articulación entre los objetivos declarados de preocupación por los derechos humanos y la promoción de la democracia con otros fines de la acción internacional de los Estados Unidos; y, la relación entre objetivos declarados y la selección de los medios al alcance de la actual administración estadounidense.

Su propósito es comprender la dirección y la intensidad de la actual política de derechos humanos de Estados Unidos y estudiar los márgenes dentro de los cuales se puede prever su evolución en el futuro.

\section{Los Derechos Humanos como grítica a la Realpolitik}

El tema de los derechos humanos surgió con fuerza en el debate de la política exterior de Estados Unidos a comienzos de la década de los setenta, como resultado de las críticas a la conducción internacional de la administración Nixon fuertemente influida por la realpolitik de Henry Kissinger ${ }^{1}$.

La preocupación surgió en el Capitolio y se expresó en la Ley de Ayuda Exterior, principal instrumento de política exterior estadounidense en cuya aprobación el poder legislativo tiene un papel decisivo, y en otras leyes relativas a la transferencia de fondos que deben ser autorizados $y$ asignados por el Congreso dentro del sistema constitucional norteamericano.

Aunque ya durante los años sesenta se habían considerado disposiciones generales sobre derechos humanos y también prohibiciones especificas para países determinados en la legislación de ayuda exterior, éstas, o habían tenido el carácter de recomendaciones o no habian logrado su aprobación legislativa. Sin embargo, en 1973 el tema se convirtió en el principal foco de la revisión de los progra-

'Para un completo análisis sobre el tema y su influencia en la política latinoamericana de Estados Unidos durante los años 70, ver: Lars Schoultz, Human Rights and United States Policy toward Latin America, Princeton University Press, Princeton, New Jersey, 1981. 
mas de ayuda económica en el Congreso. Investigadores estadounidenses señalan al golpe militar en Chile y a la discusión sobre la participación norteamericana en ese proceso, así como al debate sobre la ayuda estadounidense a las prisiones sudvietnamitas como la causa inmediata de la vinculación entre ayuda económica y represión política. El movimiento sobre los derechos humanos ha sido considerado como el heredero del movimiento contra la guerra de Vietnam, continuando la crítica a la realpolitik que orientaba la acción exterior de la administración Nixon ${ }^{2}$.

En 1973 el Subcomité sobre Movimientos y Organizaciones Internacionales, dirigido por el representante Donald Fraser, organizó un conjunto de audiencias (hearings) para analizar la situación de los derechos humanos en distintos países. Esta tarea, que hasta el periodo legislativo 1975-1976 permitió revisar diversos aspectos de la política estadounidense y los derechos humanos en 18 países, fue el antecedente principal que permitió al Gongreso introducir el respeto de los derechos humanos como una condición para otorgar ayuda exterior. "No puede darse ningún tipo de ayuda... al gobierno de cualquier país que siga un patrón consistente de transgresiones notorias a los derechos humanos reconocidos internacionalmente..., a menos que dicha ayuda vaya a beneficiar directamente a lä gente necesitada de ese pais", señala la sección 116(a) de la Ley de Ayuda Exterior modificada en 1973 por la enmienda Harlin. Sobre esta base jurídica se han fundado los intentos para limitar la ayuda económica a los regímenes represivos desde 1975.

Otro instrumento de acción exterior que fue afectado por la preocupación por los derechos humanos ha sido la asistencia militar. Ya en 1974 se agregó la sección 502B a la Ley de Ayuda Exterior que señalaba como una preocupación del Congreso -recomendación no obligatoria- "que, salvo circunstancias extraordinarias, el Presidente deberá reducir substancialmente o terminar la asistencia de seguridad a cualquier gobierno que siga un patrón consistente de notorias transgresiones a los derechos humanos internacionalmente reconocidos". De acuerdo a la definición legislativa, se estiman como transgresiones de este tipo la "tortura, el castigo o tratamiento cruel, inhumano o degradante, las detenciones prolongadas sin cargos, el causar el desaparecimiento de las personas de$\mathrm{b}$ : do a secuestro o detención clandestina de ellas, u otras denegaciones flagrantes de los derechos a la vida, libertad y seguridad de la persona...". Gomo la administración Ford hiciera caso omiso de la declaración del Congreso, en 1976 se adoptó una nueva versión, esta vez obligatoria, limitando la ayuda militar a los gobiernos transgresores de los derechos humanos a través de la Ley de Control

sTbid., p. 194. 
de Exportaciones de Armas y de Asistencia de Seguridad Internacional.

Durante el periodo 1973-1977 la actividad legislativa tendiente a denegar ayuda a un país en particular estuvo centrada en el caso de Chile. La mayoría del Congreso se enfrentó con las administraciones Nixon y Ford, las cuales se opusieron a las restricciones tanto en la discusión parlamentaria como en la fase de implementación de la ley, buscando eludir Ios límites que imponían a la ayuda estadounidense al gobierno del general Pinochet. La ayuda militar a Chile también fue objeto de restricciones durante este perfodo, aunque la acción de la administración logró suavizar las propuestas parlamentarias más severas. Con todo, la acción del Congreso empezó a influir en la propia administración Ford, la que durante sus últimos meses empezó a mencionar el tema de los derechos humanos en su discurso frente a Chile.

Desde 1977 está en vigencia otra disposición general sobre el tema: los representantes norteamericanos en los organismos financieros internacionales deben aplicar requisitos de respeto de derechos humanos a los beneficiarios de créditos de los Bancos Multilaterales de Desarrollo y otras instituciones internacionales de crédito, después que una nueva ofensiva legislativa lograra la aprobación de una fuerte legislación que condicionaba también la acción estadounidense en materia de asistencia económica multilateral

La política de la administración Carter (1977-1980) consideró los derechos humanos como un componente fundamental de la política internacional de Estados Unidos, retomando los elementos valóricos como parte de la lucha de poder internacional, tal como lo proponía la crítica de Brzezinski a Kissinger's. De esta manera la política de derechos humanos llegó a ser un elemento polémico tanto en relación a la Unión Soviética y otros países del "socialismo real", como con autoritarismos de diverso signo en el Tercer Mundo.

Con la administración Carter los derechos humanos son incorporados como uno de los elementos principales de la política exterior. La preocupación por los derechos humanos trascendió las declaraciones de política al institucionalizarse en la Oficina de Asuntos Humanitarios y de Derechos Humanos del Departamento de Estado. El antecedente de esta repartición había sido la creación de un Coordinador para Asuntos Humanitarios y de Derechos Humanos en el Departamento de Estado en 1976. Durante 1977 fue elevado al rango de Secretario de Estado Asistente, a cargo de una Oficina con el mismo rango burocrático que la Oficina de Asuntos Interamericanos y otras Oficinas regionales. El tema pasaba a tener su

sZbigniew Brzezinski, "U.s. Foreign Policy: the Search for Focus", Foreign Affairs, Vol, 51, No 4, julio $1973 \mathrm{y}$ "America in a Hostile World", Foreign Policy, No 23, verano 1976 . 
soporte burocrático, lo que permitiría el desarrollo de personal cuya preocupación central debería ser la implementación de este objetivo de política exterior. Además podría incidir en la utilización de las principales herramientas de la acción internacional norteamericana al aportar criterios en las decisiones como las relativas a ayuda económica. Por estar a un mismo nivel burocrático dentro del Departamento de Estado, la Oficina de Asuntos Humanitarios y de Derechos Humanos podia hacer pasar. las divergencias de criterio con otras reparticiones como la Agencia para el Desarrollo Internacional (AID), la Oficina de Asuntos Interamericanos u otras Oficinas para asuntos regionales, en cuanto al otorgamiento de ayuda económica a un Comité Interagencias, que era presidido por el Subsecretario de Estado. Otro elemento de permanencia del tema, al traducirse en una preocupación con efectos pertinentes, fue el establecimiento de la obligación del Secretario de Estado de transmitir anualmente a las dos ramas del Congreso un informe sobre la situación de los derechos humanos en todos los países receptores de ayuda estadounidense y en todos los países miembros de las Naciones Unidas, así como en los países receptores de asistencia de seguridad.

La aplicación de la polftica de derechos humanos durante la administración Carter no estuvo exenta de divergencias, tanto al interior del Ejecutivo, como entre esta rama y el Congreso. Más allá de la preocupación por los derechos humanos, el Ejecutivo, siguiendo una tendencia tradicional en la disputa por el poder dentro del sistema constitucional norteamericano, trató de evitar las restricciones de sus márgenes de acción impuestos por prohibiciones frente a terceros países o mediante mandatos estrictos para sus representantes en los organismos económicos multilaterales.

En relación a Chile la política de Carter fue particularmente severa: al término de la asistencia militar se agregó el voto favorable a las condenas que los organismos internacionales anualmente realizaban al gobierno militar por la situación de los derechos humanos. La negativa chilena a extraditar a tres oficiales acusados de participar en el asesinato del ex Minisro Orlando Letelier, culminó en sanciones económicas [como prohibiciones de financiamientos y garantías para proyectos de inversión norteamericanos en Chile por parte del Banco de Exportación e Importación (ExIMBANK) y de la Corporación para las Inversiones Privadas de Ultramar (OPIC)], militares (suspensión total de créditos y abastecimiento militar, reducción del personal militar en Chile e incluso la exclusión de las operaciones navales conjuntas UNITAS) y diplomáticas (retiro temporal del Embajador y disminución del personal diplomático en Santiago) 4 .

'Heraldo Muñoz y Carlos Portales, Las relaciones Estados Unidos-Chile: una amistad esquiva, Editorial Pehuén, Santiago, 1987. 
Carlos Portales / Democracia y Derechos Humanos en la politica exterior...

\section{¿LA POLÍtica DE DEReghos HUMANOS GONTRA EL INTERÉS DE EsTados UNIDOS?}

El ataque a la política de derechos humanos de Carter fue una de las banderas de los neo.conservadores en 1980. El candidato Ronald Reagan formuló una fuerte crítica a la orientación de la política exterior estadounidense desde la detente y muy especialmente a las políticas de la Administración Carter. La política del Presidente demócrata fue calificada de idealista y de ser un factor de aceleración de la decadencia del poderío norteamericano frente a la Unión Soviética.

Como contrapunto a la política de Carter, que había pretendido rehacer el consenso en la conducción de la política exterior de los Estados Unidos basándose en valores morales, en la capacidad de "administrar la interdependencia compleja" y evitando el "desmesurado miedo al comunismo" - en las palabras del Presidente demócrata-, Reagan se proponía el desarrollo de una acción decidida y firme contra el "peligro actual" (the present danger) como denominara a la Unión Soviética Norman Podhoretz, ideólogo neo-conservador que influyó sustantivamente en el movimiento que llevó a Ios republicanos a la Casa Blanca.

El programa de Reagan buscaba fortalecer el poderío económico y militar de los Estados Unidos y proyectarlo en el ámbito de las relaciones internacionales para enfrentar a los soviéticos. Esta confrontación tendría un carácter global y afectaría no sólo a las relaciones estratégicas entre las dos superpotencias, sino que volvería a signar la política internacional contemporánea con marcados tintes geopolf́ticos.

Desde esta perspectiva se criticó acerbamente la política de derechos humanos del Presidente Carter. El propósito de volver a colocar los valores morales como elemento central de la política exterior de Estados Unidos se había traducido, según los críticos, en el condicionamiento de las relaciones de Washington con otros países a la vigencia de los derechos humanos, aplicándose indiscriminadamente tanto a las relaciones con los gobiemos comunistas como a las dictaduras de distinto signo que gobiernan a muchos países del Tercer Mundo.

La critica reaganista fue articulada por su consejera Jeane Kirkpatrick, quien señaló que esa política estaba basada en supuestos conceptuales erróneos: "la política exterior de la administración Carter no fracasó por falta de buenas intenciones sino por falta de realismo acerca de la naturaleza de las autocracias tradicionales y revolucionarias, y de su relación con el interés nacional norteamericano". Según el argumento de la que iba a ser la primera embajadora de Reagan ante las Naciones Unidas, "Ios gobiernos autori- 
tarios tradicionales son menos represivos que las autociacias revolucionarias - que no son más susceptibles de liberalización- y más compatibles con los intereses norteamericanos"..., "la historia de este siglo no da razones para esperar que los regimenes radicales y totalitarios se transformen". (En cambio,) "...como muchas autocracias tradicionales permiten una réplica y participación limitadas, no es imposible que la política norteamericana pueda alentar eficazmente este proceso de liberalización y democratización, siempre que el esfuerzo no se realice en un momento en que el gobierno vigente esté luchando para sobrevivir ante adversarios violentos y que las reformas propuestas apunten a producir cambios graduales más que una democrasia serfecta de la noclie a la mañana. Para lograrlo se necesitan políticas que comprendan cómo han nacido las democracias reales...". "Una politica realista que apunte a proteger nuestros propios interees y a reforzar la capacidad de autodeterminación de naciones menos desarrolladas no necesitará enfrentar el hecho ingrato de que, si vence, la insurgencia violenta encabezada por marxistas revolucionarios difícilmente conduzca a otra cosa que a una tiranía totalitaria"b.

Esta posición que prácticamenee argüía por la supresión de la dimensión de los derechos humanos como elemento de la política exterior estadounidense fue explícitamente incorporada en el informe que en mayo de 1980 realizara el 'Comité de Santa Fe, un grupo privado constituido por varios neo-conservadores que iban a ocupar cargos en el equipo de formulación de política exterior de la administración Reagan hacia América Latina en la Casa Blanca y en el Departamento de Estado. El grupo, en el que participaron personeros como Roger Fontaine, Gordon Sumner y Lewis Tambs, señaló entre sus recomendaciones de política hacia América Latina: "Estados Unidos debe rechazar la suposición errónea de que, frente a gobiernos autoritarios, puede desarrollar e imponer fácilmente alternativas democráticas al estilo norteamericano, así como dejar de lado la convicción igualmente conflictiva de que, en tales condiciones el cambio per se es inevitable, deseable y del interés norteamericano. Esta creencia ha inducido a la administración Carter a participar activamente en el derrocamiento de gobiernos autoritarios no comunistas, a la vez que adoptaba una posición pasiva frente a Ia expansión comunista".

"La política de derechos humanos que constituye un concepto cultural y político relativo que la presente administración ha utilizado para intervenir a favor del cambio político en algunos países de este hemisferio, afectando de manera adversa la paz, la estabili-

5Jeane J. Kirkpatrick, Dictadura y Contradiccion, Editorial Sudamericana, Buenos Aires, 1983, pp. 54 a 58, 
dad y la seguridad de la región, de ser abandonada y reemplazada por una política no intervencionista de realismo político y ético".

"Estados Unidos debería cesar de dirigir hacia sus aliados su inequitativamente aplicado actual programa de derechos humanos"6.

Se establecían así las bases para volver a distinguir entre los autoritarismos en los "países amigos", -a los cuales no debería presionárseles abiertamente- y los adversarios, -frente a los cuales debería desarrollarse una lucha ideológica abierta-.

La nueva orientación no tardó en reflejarse en las declaraciones de política de los altos funcionarios de la nueva Administración. EI Secretario de Estado, general Alexander Haig, sostuvo en una presentación ante la Comisión Trilateral a comienzos de 1981 que "hay límites a los que podemos o debemos hacer para transformar las culturas, hábitos e instituciones de otros" y que si los derechos humanos se incluían en la nueva política exterior iba a ser para usarlos como un arma contra los regímenes comunistas hostiles, pero que el mejor método para corregir los malos hábitos de los países autoritarios iba a ser la fuerza "de nuestro propio ejemplo"7.

En ese contexto no sorprendió la nominación de Ernest Lefever como Secretario de Estado Asistente para Asuntos Humanitarios y de Derechos Humanos. Lefever habra señalado que la promoción de los derechos humanos en el extranjero no debía ser responsabilidad de los Estados Unidos. La nominación indicaba el propósito de alterar la preocupación por los derechos humanos en el aparato especializado creado dentro del Departamento de Estado para su supervigilancia internacional.

Esta indicación del "término" de la política de los derechos humanos de Estados Unidos tuvo efector inmediatos en países como Haití, donde se expuIsó a varios ciudadanos; en EI SaIvador, donde sịte norteamericanos fueron muertos en medio de un recrudecimiento de las violaciones a los derechos humanos; y en Gorea del Sur, donde se detuvo a más de mil opositores y sc clausuraron más de sesenta periódicos. Asimismo se produjo un acercamiento con los regímenes militares de Argentina, Chile, Guatemala y Uruguay, revirtiendo la tendencia al deterioro en las relacione bilaterales que habia tenido lugar durante la administración Carter, En las jnstituciones financieras internacionales el voto contrario a los préstamos a los regímenes militares latinoamericanos, a Corea del Sur y a Filipinas prevaleciente bajo Carter, también fue cambiado.

TInforme del Comité de Santa Fe, "Las Relaciones Interamericanas: Escudo de la Seguridad del Nuevo Mundo y Espada de la Proyección del Poder Global de Estados Unidos", en Estados Unidos: Perspectiva Latinoamericana. Cuadernos Semestrales, cIDE, México, No 9, Ier. semestre de 1981, pp. 192 y 203.

'Tamar Jacoby, "The Reagan Turnaround on Human Rights", Foreign Affairs, Summer 1986, p. 1069. 
En el caso chileno, ya en febrero de 1981 se levantó la prohibición al otorgamiento de créditos del eximbank. Luego se reanudaron las invitaciones a la Marina chileria para participar en las operaciones UNITAS, Estados Unidos volvió a votar favorablemente las solicitudes de crédito en los organismos financieros internacionales y a oponerse a las condenas en los foros internacionales de derechos humanos.

Sin embargo, la formación de una coalición de grupos de derechos humanos y su coordinación con miembros del Congreso de Estados Unidos interesados en la continuación de las consideraciones de derechos humanos como componente de la política exterior estadounidense, influyó en la decisión del Comité de Relaciones Exteriores del Senado de rechazar el nombramiento de Lefever en junio sic 1981. El cargo quedó vacante hasta octubre. El intento de erradicar completamente la política de derechos humanos llegaba a su fin, demostrando la fragmentación del poder en el sistema político estadounidense: las fuerzas que desde el Congreso habian impulsado esta política desde los años setenta consiguieron que el tema se mantuviera como foco de atención y de polémica.

$\mathrm{La}$ administración, no obstante, siguió durante esos meses intentando lograr nuevos créditos militares para gobiernos autoritarios y acercándose a los regímenes como los de Argentina, Chile y Filipinas a través de visitas de la embajadora Kirkpatrick a los dos primeros países y del vicepresidente Bush a Filipinas. Simbólicamente, el gobierno chileno expulsó al Presidente de la Comisión de Derechos Humanos cuatro días después que dejara el país la embajadora Kirkpatrick.

El Congreso continuó presionando para reponer las consideraciones de derechos humanos como elemento de la polít ca y condicionó la ayuda militar a El Salvador a una certificación periódica del Presidente de que se estaban haciendo progresos en la detención de los abusos en materia de derechos humanos.

En el caso chileno, la prohibición de la asistencia militar fue levantada, pero se condicionó su reanudación al otorgamiento de una certificación previa del Ejecutivo de un mejoramiento significativo en el respeto a los derechos humanos, así como de la cooperación del gobierno chileno en el procesamiento de los inculpados por el caso Letelier y su oposición al terrorismo internacional. Una coalición entre demócratas y conservadores moderados impusieron esta nueva limitación a los intentos más radicales de la administración de alterar la política de derechos humanos.

\section{REFORMULACIÓN DE LA POLÍTICA: DERECHOS HUMANOS $Y$ DEMOGRAGIA}

La administración debió reconocer la amplia aceptación del tema 
en el Congreso. Comenzó entonces a preparar un giro en la política que retomaba el concepto de derechos humanos, insertándolo en la perspectiva global de la politica exterior de Reagan.

El nuevo planteamiento consistió en "tratar no sólo los sintomas, sino la enfermedad". Para lograrlo se cambió el énfasis de Ia administración Garter en combatir la tortura, las desapariciones y la ausencia del debido proceso, reemplazándolo por "fomentar la infraestructura de la democracia". Sin embargo, como veremos en esta sección, el cambio no significó un retorno a la política anterior: varió la formulación presentada en la campaña de Reagan, manteniéndose muchos de los supuestos básicos del planteamiento neo-conservador. Con todo, el reclamo de un modelo democrático determinaría algunas variaciones significativas con la formulación inicial.

La principal función del nuevo planteamiento fue la reconciliación entre la ofensiva estratégica de la política exterior de Reagan y los valores del sistema norteamericano, el discurso valórico-ideológico justificando la política de poder.

Un memorándum preparado por el Subsecretario para Administración, Richard Kennedy, para el conocimiento exclusiyo del Secretario de Estado, y cuya redacción ha sido atribuida al entonces Secretario de Estado para Organizaciones Internacionales, Elliot Abrams, quien poco de"pués asumiría el cargo de Secretario de Estado para Asuntos Humanitarios y de Derechos Humanos 8 , analizó el tema de los derechos humanos en las relaciones de la nueva administración con el Capitolio. Sostenía que "la creencia del Congreso que no tenemos una política consistente de derechos humanos amenaza con desorganizar importantes iniciativas de política exterior. Los derechos humanos han llegado a ser una de las principales vías de ataque doméstico a la política exterior de la administración". Para hacer frente a este problema re prescribía que la administración tomara la ofensiva e hiciera de los derechos humanos "el corazón de nuestra política exterior", redefiniendo los derechos humanos como "derechos políticos". "Los derechos humanos -entendiendo por tales los derechos políticos y las libertades civiles- comunican lo que en último término está en el centro de nuestra disputa con el bloque soviético"日.

Esta propuesta fue adoptada. Un examen de los "Informes por países sobre las prácticas de los derechos humanos" en 1981 y 1982, muestra muy precisamente cómo la administración Reagan redefinió la política de derechos humanos, cómo la vinculó con la promoción de la democracia, bajo qué formas la rearticuló con los otros

${ }^{8}$ The New York Times, 5 de noviembie de 1981.

"Citado por Charles Maechling Jr. "Human Rights' Dehumanized", Foreign Policy, No 52, Fall 1983, p. 121. 
objetivos de la política exterior norteamericana y cómo definió el uso de los instrumentos para llevarla a cabo.

Los "Informes por países sobre las prácticas de los derechos humanos" son preparados por el Departamento de Estado y remitidos a fines de enero de cada año al Congreso. Su introducción contiene una explicación de los elementos substantivos de la política de derechos humanos de Estados Unidos. La intraducción al Informe de 1981 -entregado en enero de 1982- muestra elementos de la formulación inicial de la nueva administración, enfatizando los cambios en xelación a la política de Garter, con algunos elementos del nuevo enfoque. En cambio, en Ia introducción al Informe de 1982- de enero de 1983- se puede apreciar nítidamente la reformulación con sus nuevos énfasis.

EI Informe de 1981 señala que "la preocupación por los derechos humanos ha sido un tema constante a través de la historia americana", existiendo "un consenso fundamental en el pueblo americano en cuanto a los propósitos de la política de derechos humanos" y habiendo "desacuerdo sólo acerca de los medios para lograr estos fines"10. De esa manera, se dejaba constancia explícita de la diferencia con la política de la administración anterior.

Al definir e'. objeto de la preocupación el Informe se centra en "el derecho a estar libre de las violaciones gubernamentales contra la integridad de la persona" y en "el derecho a gozar de las libertades políticas y civiles", dejando de lado las categorías de derechos económicos y sociales.

La preocupación por los derechos humanos es vinculada directamente a la posición de poder de Estados Unidos: "ninguna nación puede llevar a la práctica una política de derechos humanos efectiva a menos que demuestre que sus principios pueden hacerla exitosa y confiada. La fuerza y el prestigio de la más poderosa nación democrática es inevitablemente importante para los derechos humanos".

Más aún, de acuerdo a la orientación de globalismo estratégico de la política erterior de Reagan, el tema está relacionado con la confrontación Este-Oeste: "...es un servicio significativo a la causa de Ios derechos humanos limitar la influencia que puede ejercer la Unión Soviética (junto con la de sus agentes y clientes). Una política seria y consistente para los derechos humanos en el mundo debe oponerse políticamente a la Unión Soviética y llamar la aten-

${ }^{20}$ Department of State, Country Reports On Human Rights Practices for 1981, Report Submitted to the Committee on Foreign Relations U. S. Senate and Committe on Foreign Affairs U.s. House of Representatives in accordance with sections 116 (d) and 502 (b) of the Foreign Assistance Act of 1961, as amended. Washington, D. G., U.s. Government Printing Office, 1982. Las citas que siguen están tomadas de este documento. 
ción una y otra vez sobre las violaciones a los derechos humanos en el bloque soviético".

El Informe recoge la crítica neo-conservadora a los efectos de Ia aplicación de la política de derechos humanos frente a dictaduras en países afines: "Estados Unidos debe continuar respondiendo a serios problemas de derechos humanos en países amigos", no se seguirá "una política de indignación selectiva", pero, "por supuesto, los medios disponibles... para detener apropiadamente tales violaciones de los derechos humanos siempre varían en cada caso específico. Nuestra respuesta específica a las violaciones de los derechos humanos difiere apropiadamente de país a país, pero la intensidad de nuestra preocupación no debería cambiar". Esta política nos forzará "a hacer difíciles elecciones entre la necesidad de responder a las violaciones de los derechos humanos y otros intereses de política exterior como el comercio y la seguridad. En algunos casos tendremos que aceptar el hecho que las relaciones bilaterales con un país amigo pueden ser dañadas debido a nuestra preocupación por los derechos humanos. Este es el precio inevitable de una política consistente". Pero, a renglón seguido se señala: "Sin embargo, una política realista debe estar alerta no sólo a las violaciones de los derechos humanos realizadas por los gobiernos, sino también a aquellas realizadas por los grupos de oposición". El esfuerzo para controlar a los "grupos terroristas" es así vinculado a la política de derechos humanos de Estados Unidos.

El tema de los efectos de la política sobre los gobiernos autoritarios amigos de Estados Unidos es desarrollado aún más:

"Un problema continuo para la política de derechos humanos es el hecho de que tradicionalmente tiene como propósito afectar la conducta interna de otros países, en circunstancias que los gobiernos son reticentes a cambiar el sistema polftico de sus naciones por razones de política exterior. La capacidad de presión que Estados Unidos tiene es más fuerte en países amigos, donde tenemos más acceso y más influencia. Tal influencia es un recurso importante en la búsqueda de los derechos humanos, pero su concentración en los países amigos crea un peligro: la política de derechos humanos podría subrayar y castigar las violaciones de los derechos humanos en los países amigos, otorgándole inmunidad a los países hostiles. $\mathrm{Si}$ ello sucede no representaría equitativamente la distribución de abusos a los derechos humanos en el mundo. Más aún, una nación que llegue a mostrar un patrón general de enemistamiento con o socavamiento a gobiernos amigos podría obviamente limitar su futura influencia sobre su conducta de derechos humanos". Se concluye señalando "la necesidad de evitar presionar solamente donde nuestra influencia es mayor en vez de hacerlo donde los abusos son más grandes". 
Se postulaba que estos criterios fueran decisivos en la selección de los medios a utilizar para lograr los objetivos de la política de derechos humanos. Estos instrumentos son, según el Informe: la revisión de la transferencia de equipos militares y policiales, las discusiones francas con funcionarios extranjeros, las reuniones con las víctimas de los abusos a los derechos humanos, y - "donde la diplomacia privada (que después iba a ser denominada "diplomacia silenciosa") no está disponible o sea inútil- declaraciones públicas cie preocupación". "Estos instrumentos son aplicados en una forma que tenga en cuenta la historia, la cultura y el ambiente político actual de un país y que reconozca que la preocupación por los derechos humanos debe ser balanceada con otros intereses fundamentales". Se reconocía la relativización de la política realizada por la administración Reagan. Para ésta debía primar "el criterio de efectividad", enfatizándose "la diplomacia tradicional" y "minimizándose las reacciones contraproductivas".

Durante ese primer año de Reagan, según explica el Informe, Estados Unidos tomó el liderazgo en "la oposición a los dobles estándares aplicados a las violaciones a los derechos humanos en los foros internacionales" y buscando promover "enfoques regionales para resolver las preocupaciones internacionales sobre derechos humanos". En la práctica, significó la oposición a los tratamientos de las violaciones de los derechos humanos en varios países latinoamericanos en los órganos de las Naciones Unidas y el enfoque de la preocupación en el caso soviético, en particular durante la reunión de Madrid de la Conferencia de Seguridad y Cooperación en Europa.

Finalmente, el Informe contiene un nuevo elemento que será desarrollado en los años siguientes, una "política positiva" que evite "limitar el rango de acción de nuestra política de derechos humanos a responder a las violaciones individuales de los derechos humanos cuando ellos aparezcan". Se trata de ayudar a la emergencia gradual de sistemas políticoj libres.

El 8 de junio de 1982, el Presidente Reagan, en un discurso pronunciado ante el Parlamento Británico, el lugar donde "los derechos de los hombres libres y los procesos de representación han sido debaticios y refinados", lanzó su campaña global por la democracia. Señaló que la amenaza de guerra global y la amenaza a la libertad humana debida al enorme poder del Estado moderno provienen del totalitarismo. Para combatirlo propuso "fomentar la infraestructura de la democracia -el sistema de la prensa libre, sindicatos, partidos políticos, universidades- el cual permite al pueblo escoger su propio camino, reconciliar sus diferencias a través de medios pacíficos". Los líderes de los dos principales partidos políticos, seña- 
laba el Presidente, están estudiando cómo Estados Unidos puede contribuir mejor a la campaña global por la democracia ${ }^{11}$.

Esta nueva formulación fue recogida por el Informe sobre los derechos humanos de 1982, que enfatiza "la participación polftica es no sólo un derecho importante en sí mismo, sino que la mejor garantía de que los otros derechos serán observados". "La participación política en el verdadero sentido sólo puede existir en una democracia, aunque hay casos de países que son parcialmente democráticos". Reforzando la vinculación entre democracia y derechos humanos y más precisamente entre la concepción norteamericana de la democracia y la vigencia de los derechos humanos, el Informe precisa: "la intención de los originadores de los derechos humanos, entonces, parece haber sido seleccionar de un amplio rango de cosas que el hombre necesita o quiere, ciertas cosas cruciales a que ellos tienen derechos por su propia naturaleza -derechos humanos- Ios cuales cuando son cumplidos crearán las precondiciones para la satisfacción de otras necesidades. Estas precondiciones son creadas - de acuerdo a esta interpretación- por un sistema poÍ́tico de elección de las leyes y de los funcionarios que gobiernan a los hombres y por un sistema económico que permite a los individuos comprometerse libremente en diversas aproximaciones a la 'búsqueda de la felicidád'". Después de reafirmar la discrepancia básica con la Unión Soviética en materia de derechos humanos y las dificultades de llevar a cabo una política efectiva frente a las violaciones de los derechos humanos en países amigos, reafirma la importancia del tema: "Ios derechos humanos están en el corazón de la política exterior norteamericana, porque esto es central a la concepción que América tiene de sí misma". Estados Unidos fueron creados "para hacer real una visión política especifica". De ello sigue que "los 'derechos humanos' no sean algo agregado a nuestra política exterior, sino su propósito último: la preservación y la promoción de la libertad en el mundo"12.

Se había producido "un cambio en 150 grados" en la polftica de derechos humanos de la administración Reagan ${ }^{13}$.

En la introducción al Informe de 1983 se profundiza la elaboración sobre la relación entre derechos humanos, democracia y política exterior estadounidense. El Informe introduce una nueva catego-

ב1"President Reagan"s Address", London, June 8th. 1982, Department of State Bulletin, July 1982, pp. 24-29.

IDDepartment of State, Country Reports On Fuman Rights Practices For 1982, Report Submitted to the Committee on Foreign Relations U.s. Senate and Committee on Foreign Affairs U.s. House of Representatives in accordance with sections 116 (d) and 502 (b) of the Foreign Assistance Act of 1961, as amended. Washington, D. C., U.s. Government Printing Office, 1983.

${ }^{13}$ Tamar Jacoby, op. cit., p. 1071. 
ría de derechos humanos junto al derecho a la integridad de la persona y a las libertades políticas y civiles, el derecho de los ciudadanos a cambiar su gobierno. Debido a "que los derechos políticos tienden a determinar la conducta en muchas de las otras categorías, (éstos) han sido elevados de una subcategoría a una categoría en sí misma", de acuerdo a la nomenclatura del Departamento de Estado:

El establecimiento de estos derechos políticos constituye, de acuerdo a la nueva definición, el aspecto positivo de la polftica de derechos humanos de la administración Reagan. "Al mismo tiempo nos hemos enfrentado a la necesidad de crear a largo plazo un sistema de gobierno que institucionalice la protección de los derechos humanos. Así como la creación de un sistema económico que promueva el crecimiento y la prosperidad es una mejor solución a largo plazo para el problema de la pobreza que actos repetidos de caridad, así también, la creación de un sistema de gobierno que salvaguarde los derechos humanos es una mejor respuesta a largo plazo para el problema de los abusos a los derechos humanos que repetidas representaciones diplomáticas caso por caso".

El Informe señala que la política de fomento de la democracia a través del mundo formulada por el Presidente Reagan en Londres, se concretó en la creación del Fondo Nacional por la Democracia (National Endowment for Democracy), que permitirá expandir la participación en estas tareas de los dos principales partidos políticos estadounidenses, así como de los sectores del trabajo, de los negocios y otras instituciones privadas.

El Informe analiza extensamente la relación entre la vigencia de los derechos humanos y el funcionamiento de un sistema democrático, dándole el carácter de modelo al sistema político y social de Estados Unidos. La relación entre sistema político democrático con diversidad y pluralismo social, operando bajo el principio de la igualdad, es la garantía para reconciliar gobierno de mayoría con los derechos de la minoría, señala el Informe. En seguida contrasta este modelo en el cual "la sociedad es el guardián de los principios del pais", con el modelo soviético en el cual "la realización de los principios políticos está confiada enteramente al gobierno central". Así, el tema de los derechos humanos que había sido objeto de acerbas críticas durante la campaña contra el Presidente Carter habia quedado perfectamente inserto en la preocupación ideológica de la política exterior de la administración Reagan.

Más aún, la distinción entre totalitarismos y autoritarismos, formulada por Kirkpatrick, es retomada en los siguientes términos: "Esta distinción entre dictaduras comunistas y no comunistas tiene implicaciones obvias para la política de derechos humanos. Todas las dictaduras, tanto las de izquierda como las de derecha, partici- 
pan en serias violaciones a los derechos humanos. Todas las violaciones a los derechos humanos, en su momento, merecen ser condenadas. Pejo mientras que las dictaduras no comunistas son capaces, en grados variables, de evolucionar hacia la democracia, las dictaduras comunistạs son singularmente resistentes a la democratización". Por ello, "Ia prevención de establecimiento de las dictaduras comunistas deberfa ser una prioridad especialmente alta de cualquier polftica de derechos humanos seria y realista", concluye el Informe del Departamento de Estado.

Con todo, el esquema se aleja de algunas conclusiones de los teóricos neo-conservadores. Señala el Informe que "la experiencia del trabajo práctico en materia de derechos humanos fortalece eI análisis que nos lleva del trabajo de caso sobre derechos humanos hacia el enfrentamiento de los problemas sistémicos. Muestra que si vamos a producir cambios importantes en las condiciones de los derechos humanos, sólo podemos hacerlo cambiando los sistemas políticos, alentando a la democracia". Al proponer esta tarea, ataca tres falacias - las dos primeras vinculadas al pensamiento neoconservador-: que la democracia sería un fenómeno exclusivo del Atlántico Norte, lo que partiría "del supuesto relativista que la atracción de la libertad no deriva de algo inherente a la naturaleza humana, sino que es el mero resultado de una forma particular de condicionamiento cultural", que el Informe niega; que la democracia sólo podría existir en sociedades afluentes, lo que es rechazado; $y$, que la promoción de la democracia sería incompatible con la paz, puesto que significaria la interferencia en los asuntos internos de otros países, lo que es negado, señalando que la política de promoción de la democracia debe ser llevada a la práctica en un proceso gradual, comenzando por el fortalecimiento de sus fundamentos, en lo que retorna a uno de Ios puntos de Kirkpatrick ${ }^{14}$.

La nueva política de derechos humanos y su relación con las orientaciones más generales de la política exterior de la administración Reagan quedaron netamente perfiladas en el discurso que el Secretario de Estado Shultz realizara en Peoria, Illinois, el 22 de febrero de 1984. En esa ocasión señaló que la política de derechos humanos se funda en la esencia nacional de Estados Unidos. Ésta no se define por el origen común de sus ciudadanos, sino por Ias creencias en un conjunto de valores compartidos: la libertad, la democracia constitucional y la tolerancia religiosa y racial. Estos va-

${ }^{1}$ Department of State, Country Reports On Human Rights Practices For 1983, Report Submitted to the Committee on Foreign Relations U.s. Senate and Committee on Foreign Affairs U.s. House Representatives in accordance with sections 116 (d) and 502 (b) of the Foreign Assistance Act of 1961, as amended. Washington, D. C., U.s. Government Printing Office, 1984. 
lores son definidos como un poderoso impulso para la política exterior de Estados Unidos.

Sin embargo, la recuperación de los derechos humanos no debe llevar a políticas erróneas como el "escapismo" o la de adoptar posturas de disociación frente a las dictaduras, pues ello restringiría la capacidad de influencia de Estados Unidos, careciendo de efectos prácticos. Tampoco comparte el Secretario de Estado "la política de derechos humanos ... como una fórmula para restringir los compromisos americanos en el exterior. Perversamente, de acuerdo a este modo de pensar, un gobierno amigo de nosotros está sujeto a un escrutinio más riguroso que otros; se atacan nuestros lazos de seguridad con él, y cuando ese gobierno enfrenta una amenaza interna o externa, sus defectos morales son destacados como una excusa para abandonarlo".

Tales enfoques, según Schultz, suponen una concepción diferente del papel de Estados Unidos y de su impacto en el mundo y no una diferencia en cuanto a la concepción de derechos humanos. Postula en cambio, un compromiso activo, de acuerdo a los valores y a los intereses de Estados Unidos en el mundo, "actuando orgullosamente como los campeones de la libertad".

La aplicación de la política de derechos humanos en todo caso, señala el Secretario de Estado, debe considerar los límites de "nuestra capacidad para rehacer el mundo"; que "los gobiernos soberanos decidirán por sí mismos, a pesar de las presiones externas"; que para los gobiernos basados en la represión, Ios derechos humanos inevitablemente serán subordinados a los requerimientos percibidos para su sobrevivencia política; y tener en cuenta los límites que surgen de la diversidad y complejidad de las situaciones internas de otros países". "Cómo usamos nuestra influencia y cómo reconciliamos los intereses morales y políticos son preguntas que no pueden ser respondidas en forma dogmática, sino mediante análisis cuidadosos y sensatos y con no poca humildad".

En la puesta en práctica de la política destacan cuatro dilemas: 1) la preocupación por los derechos humanos y su efecto sobre la seguridad regional o internacional; 2) el conocimiento adecuado de las realidades internas y culturales de otros países y el efecto de alentar la moderación o empeorar la situación que puede provenir de una determinada aplicación de la política de derechos humanos; 3) la importancia de la preocupación del Congreso norteamericano y las dificultades que pueden surgir de las limitaciones legislativas para el Ejecutivo; y 4) las dificultades de aplicar esta política frente a estados totalitarios.

Termina, nuevamente, postulando que "la esencia del problema es el tipo de estructura política que hace posible los abusos a los 
derechos humanos" y señalando que "por esto el Presidente Reagan ha puesto tanto énfasis en la democracia"15.

Respondiendo a los críticos del nuevo enfoque, el Secretario Shultz señalaba en 1985, siguiendo a Hans Morgenthau, que el dilema de la política exterior es entre "principios morales divorciados de la realidad política y principios morales derivados de la realidad política". Tenemos que aceptar que "nuestro compromiso vehemente con los principios morales no puede ser un sustituto de una política exterior sólida en un mundo de duras realidades y elecciones complejas".

Sin embargo, precisa Shultz, "la realidad de hoy día es que nuestros principios morales y nuestros intereses nacionales pueden estar convergiendo, por necesidad, más que nunca...". "Nuestra seguridad y bienestar aumentan en un mundo donde la democracia florece y donde el sistema económico global es libre y abierto. No podemos esperar sobrevivir mucho tiempo si nuestros socios democráticos sucumben al totalitarismo".

Sin embargo, "tenemos amigos y aliados que no siempre viven de acuerdo a nuestros estándares de libertad y gobierno democrático, sin embargo no podemos abandonarlos"... "Tendremos frecuentemente que aceptar la realidad que los avances hacia la democracia y mayor libertad en algunas importantes naciones pro-occidentales pueden ser lentos y requerirán de paciencia". "Si usamos nuestro poder para empujar demasiado lejos a nuestros aliados no democráticos podemos, de hecho, destruir la esperanza de mayor libertad, y también podemos encontrar que los regímenes que inadvertidamente llevamos al poder son el peor de los dos mundos: pueden ser a la vez hostiles a nuestros intereses y más represivos y dictatoriales que aquellos que buscábamos cambiar"16.

Algunos meses más tarde, después de la caida de las dictaduras de Duvalier en Haití, y Marcos en Filipinas, el Secretario de Estado enfatizaba que "el movimiento hacia la democracia nos da una nueva oportunidad para promover los interess nortamericanos con sólo un modesto compromiso de nuestros recursos"17.

\section{SIGNIFICADO Y PROYECGIONES DE LA NUEVA POLfTICA}

¿Cuál es el significado de este proceso por el cual la Administración Reagan transita desde la crítica frontal a la política de derechos

${ }^{15}$ George Shultz, "Human Rights and the Moral Dimension of v.s. Foreign Policy", Department of State Bulletin, April 1984, pp. 15-19.

${ }^{10}$ George Shultz, "Morality and Realism in American Foreign Policy", Department of State Bulletin, December 1985, pp. 26-28.

${ }^{17}$ George Shultz, "Moral Principles and Strategic Interests: The Worldwide Movement Toward Democracy", Department of State Bulletin, June 1986, pp. 35-39. 
humanos de Carter hacia la recuperación del tema en el discurso gubernamental y al ulterior cambio de énfasis en favor de la promoción de la democracia? ¿ ¿Gómo se ha expresado este proceso en la política efectivamente aplicada por la Administración en relación a la situación de los derechos humanos en otros países?

¿Qué proyección tendrán las consideraciones de derechos humanos en la futura política exterior de Estados Unidos?

Para responder a estas interrogantes analizaremos brevemente el papel de los elementos valóricos en la política exterior estadounidense; la influencia de la estructura de poder fragmentada del sistema constitucional estadounidense sobre el proceso de formulación de políticas; y la relación entre los factores políticos y las estructuras burocráticas en la determinación del contenido de las políticas de la administración norteamericana.

\section{A. Valores y legitimación de la política exterior}

La posición de Ia Administración Reagan, que comenzó con una crítica al idealismo de la Administración Carter por su política frente a los "gobiernos autoritarios amigos", iba a culminar en marzo de 1986 con la proclamación del Presidente Reagan de su oposición a las dictaduras tanto de izquierda como de derecha, alejándose significativamente de la formulación inicial de Kirkpatrick. La Administración Reagan, "habiendo abandonado el esfuerzo para disminuir la importancia del tema, (de los derechos humanos) buscaba, en efecto, cooptar la idea y usarla para sus propios propósitos geopolíticos, definidos en forma más bien estrecha"18.

Se imponía la necesidad de encontrar un factor de legitimación de la política que recurriera a valores éticos. La pura expresión de política de poder ha sido difícilmente aceptada en periodos largos dentro del consenso político predominante en Estados Unidos, a menos que se la reconcilie con las formulaciones valóricas aceptadas o que sea justificada por su éxito. La búsqueda del poder debe llevar al éxito y encontrar alguna justificación valórica. Esta justificación, en una nación fundada en su sistema político democrático, ha sido la capacidad de expansión de su propio sistema. Su expresión puede cambiar en sus manifestaciones históricas -la extensión de la democracia, el fomento de la forma de vida norteamericana, - la preservación de los derechos humanos a escala internacionalpero la invocación ética siempre es necesaria para lograr la mantención del apoyo público de una política exterior determinada. No se trata, sin embargo, que la política lleve efectivamente al cumpli-

${ }^{18}$ Tamar Jacoby, op. cit., p. 1071. 
miento de Ios objetivos morales que se proclaman, sino que sea percibida de esa manera dentro del sistema político norteamericano.

El razonamiento kissingeriano de equilibrio de poder, que dejaba de lado este componente ético, prevaleció durante el apogeo de la Administración Nixon, pero sucumbió frente a la crítica de amoralismo que le formularon los demócratas en 1976 ,cuando el éxito de la política era menos evidente para la opinión pública.

Los demócratas propiciaron en 1976 devolver el sentido moral a la política internacional de Estados Unidos. A través de la política de derechos humanos enfatizaron la importancia de la lucha ideoIógica que, según Brzezinski, los norteamericanos estaban perdiendo a nivel global. De esta manera se pretendía reconciliar el elemento valórico con los objetivos de poder de Estados Unidos a escala mundial19.

A su vez, la reelección de Garter en 1980 fue sepultada por la percepción interna de falta de éxito Iuego de la revolución sandinista, de la invasión soviética a Afganistán y, fundamentalmente, de la captura y mantención de los rehenes norteamericanos por el régimen iraní. Los republicanos lograron proyectar la imagen de un Presidente con un discurso ético incapaz de conseguir la consecución del interés norteamericano.

Sin embargo, como se demostró en los primeros meses de 1981, la mera apelación al realismo político, que caracterizó el discurso de Reagan durante la campaña, no fue suficiente para sustentar ideológicamente Ia nueva política exterior de su Administración. De ahí la necesidad de recuperar el tema de los derechos humanos. $\mathrm{Su}$ transformación en "política positiva", -la democracia como la mejor estructura capaz de garantizar la vigencia de los derechos humanos-, permitió adecuar esta política al objetivo de confrontación ideológica global con los soviético; sustentado por la Administración. Mientras que la preocupación por la observancia de los derechos humanos como eje ponía el acento en la comprobación de la conducta gubernamental expresada en casos precisamente singularizables, la promoción de la democracia - tal como es entendida por Washington- relaciona directamente el aspecto valórico con la difusión y fortalecimiento del modelo norteamericano en el mundo, de manera tal que se confunde con la confrontación ideológica global.

La calificación de si un sistema político se acerca más o menos al modelo estadounidense y la percepción de las tendencias de su evolución, han permitido a la Administración graduar con gran la-

\footnotetext{
${ }^{28}$ Carlos Portales, "Problemas de Consenso en la Polftica Exterior Norteamericana" en Carlos Portales (comp.), La América Latina en el Nuevo Orden Económico Internacional, Fondo de Cultura Económica, México, 1983, pp. 17-48.
} 
xitud la intensidad de su polftica de "promoción de la d $r$ mocricia". El contenido de esta política ha sido llenado con un aruplio espectro de medidas que van desde el apoyo al desarrollo de actores $f$ instituciones que permitan el funcionamiento de ese sistema políti co, a la celebración de elecciones, hasta la lucha por el derrocamien. to de regímenes calificados de totalitarios.

El cambio de énfasis no significa que los derechos humanos hayan sido completamente borrados de la política exterior de Reagan. No obstante, esta preocupación de Ia Administración ha sido puesta en el contexto de los diversos intereses de la politica exterior norteamericana. Para el Secretario de Estado Asistente Abrams los derechos humanos "no son un objetivo flotante para ser considerado aisladamente cada mañana. No traicionamos la causa de los derechos humanos cuando hacemos juicios prudentes acerca de lo que podemos y no podemos hacer en un lugar en un determinado momento". De acuerdo a su visión es necesario dar prioridad a la efectividad, lo que supone subordinar el interés por la vigencia de los derechos humanos a las más amplias preocupaciones geopolíticas de la nación. "No es suficiente -señalaba a un periodista en 1982-, preguntar quién está en el poder y qué parece. Tenemos también que preguntarnos cuál es la alternativa, cuáles son las posibles perspectivas de mejorar la situación"20.

La necesidad de legitimar la política exterior de la Administración Reagan dentro del sistema político estadounidense llevó a retomar el tema de los derechos humanos. EI tema persistió así como preocupación internacional de Estados Unidos, aunque subordinado a los fines geopolíticos de la nueva posición internacional.

\section{B. Fragmentación de los poderes constitucionales}

Un segundo elemento que permite comprender la mantención de la política de derechos humanos a pesar de los embates reaganistas de 1980 y evaluar la futura proyección de esta política después de 1988, es la indole de la organización constitucional estadounidense y su efectivo reparto del poder entre el Ejecutivo y el Congreso.

La formación de la ley requiere la concurrencia de la voluntad de las autoridades de la Casa Blanca y del Capitolio; poderes elegidos en forma independiente. De tal manera que el proceso de aprobación de la ley permite la negociación entre Ejecutivo y Congreso en la determinación del contenido de las políticas estatales sancionadas a través de la legislación. La aprobación de los presupuestos y de las autorizaciones de gastos son los instrumentos de negociación más importantes en manos. del Congreso para alterar

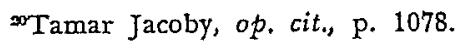


las proposiciones del Presidente. La legislación de ayuda exterior se ha transformado en el vehículo de influencia sistemática más común que tiene el Congreso en la conducción de la política exterior norteamericana. La aprobación de los tratados, así como la del nombramiento de altos funcionarios gubernamentales, que corresponden al Senado, son las otras vías importantes que esta rama del Capitolio tiene para influir en la conducción internacional estadounidenses.

Por otra parte, los partidos políticos estadounidenses son estructuras electorales sin uniformidad ideológica y los congresistas y senadores no obedecen a rígidas disciplinas de partido en su acción legislativa. Estas características de los actores políticos permiten la formación de grupos y coaliciones que actúan en la tarea legislativa con gran flexibilidad y permiten un amplio campo de negociación tanto al interior del Congreso como en su relación con el Presidente. De esta manera un grupo consistente que tenga una preocupación definida - como el tema de la protección internacional de los derechos humanos-, aunque no sea mayoritario, puede ejercer su influencia a través de la negociación, otorgando apoyos a otros grupos interesados en temas distintos a cambio de respaldo a medidas consistentes con su foco de preocupación principal.

La característica ideológica plural de los partidos y la carencia de disciplina partidaria rígida, basada fundamentalmente en la relación directa entre el senador o representante y su electorado (constituency), posibilitan la acción de los grupos de interés organizados a través de los lobbies.

La preocupación del 'Congreso por el tema no desapareció con la llegada de Reagan a la Casa Blanca, precisamente debido a la existencia de grupos de parlamentarios preocupados por la mantención de los derechos humanos en la agenda exterior de Estados Unidos y a la acción de los grupos de presión organizados sobre derechos humanos. La preocupación de los primeros se manifestó desde el. comienzo de Ia Administración y con el rechazo del nombramiento de Lefever provocó el cambio en la posición de la Administración, que recuperó el tema en el discurso de su política exterior.

Estos miembros del Congreso han criticado la falta de consistencia en la aplicación de una política de derechos humanos y de hecho han establecido ciertos límites a la negligencia frente a las violaciones de los derechos humanos cometidas por los regimenes autoritarios en América Latina y otras partes del mundo. La preocupación de los grupos de derechos humanos que ha formado verdaderos lobbies, manteniendo la atención sobre el tema, también ha tenido como uno de sus canales de influencia al Congreso. 


\section{La creación de estructuras burocráticas y la legislación sobre protección de los derechos humanos}

No sólo la necesidad de legitimación de la política exterior y el hecho de compartir el poder dentro de la estructura política estadounidense influyeron en la "necesidad" de una nueva política de derechos humanos, sino también las obligaciones establecidas en la ley de tomar en cuenta la vigencia de los derechos humanos en la adopción de medidas tales como la aprobación de créditos en los organismos financieros internacionales. Aunque la Administración no ha considerado obligatoria esta legislación, sino solamente uno de los criterios para adoptar sus decisiones ${ }^{21}$, la existencia de estas normas ha permitido al Congreso revisar la aplicación de la política a través de audiencias hearings, en las cuales los funcionarios gubernamentales deben informar a los congresistas de la aplicación de la legislación y ulteriormente adoptar posiciones que condicionan la política gubernamental.

Otro elemento de persistencia de la preocupación han sido los informes sobre la situación de los derechos humanos que el Departamento de Estado debe entregar anualmente al Congreso y que sirven de antecedente para la adopción de medidas legislativas, particularmente en relación a los programas de asistencia económica y militar. Estos informes son redactados por el Departamento de Estado sobre la base de informaciones recogidas por las Embajadas de Estados Unidos. En cada Embajada se ha encargado a un funcionario la preparación de dichos informes. Para realizar esta tarea ellos deben vincularse con las realidades locales a fin de evaluar e. respeto de los derechos humanos en el respectivo país. De esta manera, la preocupación se convierte en una actividad cotidiana de las misiones diplomáticas y la posibilidad de un conocimiento informado de la situación, aumenta. La existencia de estos funcionarios, junto al trabajo de la Oficina de Derechos Humanos en Washington, han creado un conjunto de diplomáticos cuya misión es relevar el tema dentro de la formulación de la política exterior estadounidense $y$, por lo tanto, generar la persistencia de la preocupación por el tema en la formulación de la política exterior.

\section{El debate sobre los derechos humanos durante la Administra- ción Reagan}

Hasta fines de 1981 la controversia se dio entre la continuación de una política de derechos humanos frente al intento de superarla

IDeclaración del Subsecretario Abrams citada en Cynthia Brown (ed.), With Friends Like These. The Americas Watch Report on Human Rights and U.s. Policy in Latin America. Pantheon Books, New York, I985, p. 23. 
-o de suprimirla - esgrimido por los altos funcionarios del nuevo gob:erno.

En cambio, después del giro realizado a fines del primer año de la Administración, el debate se centró en la efectividad de la nueva política de derechos humanos $y$, particularmente, en la calidad de lós informes sobre la situación de los derechos humanos en varịos paísés realizada por la Administración Reagan. Éstos han sido puestos, en duda muchas veces por las organizaciones no gubernamèntales que promueven los derechos humanos. En los casos de países definidos como cruciales para el interés norteamericano por la Administración, la controversia no ha sido sobre la importancia que teóricamente se concede al tema, sino sobre la apreciación concreta de si los derechos humanos son efectivamente respetados o transgredidos y si la situación está en vías de progreso o empeoramiento. En otras palabras, se ha tratado de una disputa sobre los hechos efectivamente acaecidos y sobre su interpretación. Este es el tipo de controversia sobre los derechos humanos que se ha suscitado en los casos de pafses centroamericanos como El Salvador. Guatemala y Nicaragua. En relación al primero, el Congreso estableció en 1981 la condición de certificar semestralmente el progreso en la situación de los derechos humanos como prerrequisito para el desembolso de los fondos de ayuda exterior. Las certificaciones de progreso en la situación de los derechos humanos en El Salvador, asi como Jos informes sobre otros países centroamericanos, han sido el centro de las más importantes disputas sobre el tema durante la Administración Reagan ${ }^{22}$.

La necesidad de mantener credibilidad en el proceso de certificación fue un factor muy importante que impidió durante un largo período la certificación de una mejoría de la situación de los derechos humanos en Chile. Esa declaración del Ejecutivo habia sido establecida por el Congreso como un prerrequisito para reanudar Ja ayuda militar y varios de los programas de ayuda económica bilateral a Chile en 1981 al modificarse la Enmienda Kennedỳ. Desde ese año hasta 1983 se habló de la inminencia de tal certificación y aunque muchos funcionarios de la Administración la favorecieron, el costo político en el Congreso que habría generado tal medida fue un disuasivo importante que previno su adopción. Con posteriori-

mIbid., pp. I4-19 y 112-204. Los grupos de derechos humanos emiten varios informes que evalúan la polftica de derechos humanos de la Administración Reagan. Ver por ejemplo: Americas Watch, Helsinki Watch \& Lawyers Committee for International Human Rights, Failure; The Reagan Administration's Human Rights Policy in 1993, New York. January 1984; The Watch Committees \& Lawyers Committee for Human Rights, The Reagan Administration's Record on Human Rights in 1985, New York y Washington, January 1986; The Watch Committees \& Lawyers 'Committee for Human Rights, The Reagan Administrations's Record on Human Rights in 1986, New York y Washington, February 1987. 
dad a 1983, la evaluación del prop:o Ejecutivo - dentro de la cual seguía considerándo e la relación con el Congreso- alejó las posibilidades de extender esa certificación frente a la persistencia del régimen autoritario chileno y de sus prácticas transgresoras de los derechos humanos.

Una característica central de la nueva política ha sido la subordinación de las criticas a las transgresiones a los derechos humanos en países aliadoj a otros elementos de la política exterior. Aunque se reintrodujo el tema para neutralizar la oposición de los grupos pro.derechos humanos y de ciertos miembros del Congreso, se estableció como límite a dicha política la potencial desestabilización de los gobiernos autoritarios pro-norteamericanos que una presión muy fuerte en relación a la situación de los derechos humanos pudiere provocar. De ahí que en el caso de El Salvador se otorgaran las certificaciones a pesar de la evidencia de que la situación no estaba mejorando. También en el caso de las Filipinas desde la visita del Vicepresidente Bush en 1981 primó una política de apoyo con críticas al gobierno de Marcos y sólo al final de ese gobierno, cuando se había producido la insurrección cívico-militar, el gobierno de Estados Unidos retiró el apoyo al dictador. En el caso de la política frente a Sudáfrica, la estrategia de "compromiso constructivo" otorgaba prioridad a la mantención de los lazos entre Estados Unidos y el régimen sudafricano: la presión por el cambio estaba subordinada a los intereses estratégicos norteamericanos en la región.

Este enfoque del gobierno da prioridad a la efectividad, y subordina a los derechos humanos a las preocupaciones geopolíticas del país, a diferencia de Ja posición de los grupos pro-derechos humanos que valoran primordialmente la vigencia de tales derechos.

\section{E. El acento en la democracia y su efecto en la politica de derechos humanos}

La transformación de foco de la preocupación exterior desde los derechos humanos a la democracia -entendida como el mejor sistema de organización política para la vigencia efectiva de los derechos humanos- no significa ni que la democracia se instaure inmediatamente -ritmo por lo demás que explícitamente no es buscado por la Administración-, ni que en el proceso que la política de la Administración Reagan define como de transición a la democracia no se produzcan transgresiones a los derechos humanos.

Es lo que ha sucedido en la política frente a América Central. Ya en 1982 la promoción de la democracia fue proclamada como el objetivo de la política para esa región ${ }^{23}$, convirtiéndose en la li-

Declaración sobre la democracia en América Central del Departamento de Estado, 5 de octubre de 1982, Department of State Bulletin, diciembre de 1982, pp. 69 y 70. 
nea articuladora de la estrategia del gobierno estadounidense $e^{24}$. Esa polf́tica se operacionalizó como apoyo a la guerrilla antisandinista, esto es, como parte de la lucha global por el poder.

La centralidad del tema de la democracia dentro de la visión Este-Oeste quedó institucionalizada el 7 de febrero de 1983 al establecerse en la Gasa Blanca un grupo de planificación especial bajo la presidencia del Asistente del Presidente para Asuntos de Seguridad Nacional y en el cual participaban el Secretario de Estado, el Secretario de Defensa, el Director de la Agencia de Información de Estados Unidos, el Administrador de la AdD y el Asistente del Presidente para Comunicaciones ${ }^{25}$. En este marco ideológico se desarrollaron iniciativas como el Proyecto Democracia, cuyas actividades fueron reveladas a fines de 1986 en las investigaciones sobre el caso Irán cóntras realizadas por una Comisión Especial del Ejecutivo presidida por John Tower, por el Congreso y por fiscales especiales. El análisis del completo significado de este proceso debe ser objeto de, estudios futuros, sin embargo desde ya pueden visualizarse las consecuencias de la cadena argumental basada en la conexión protección a los derechos humanos -establecimiento de un régimen democrático, tal como es definido por el Ejecutivo norteamericanolucha por apoyar ese tipo de régimen (o, lo que es definido como equivalente, el derrocamiento del régimen definido por el mismo Ejecutivo como totalitario) -violación de los derechos humanos en la Jucha. En la ejecución de esta cadena, como lo demuertra la reciente investigación y los testimonios en el Congreso de Estados Unidos, se ha parado sobre y al margen de los canales institucionales del gobierno norteamericano y aun contra su propia legislación. con resultados de severas transgresiones a los derechos humanos. E] apoyo a la guerrilla de los contras (Iuchadores por la libertad" en la terminología de la Casa Blanca) ha sido realizado en nombre de la política por los derechos humanos y la democracia ${ }^{26}$.

En otros países como Haití, Filipinas y Chile la promoción de derechos humanos ha coincidido en la visión del ejecutivo norteamericano con los intereses estratégicos de Estados Unidos. Se han dado pasos cautelosos y muchas veces se ha actuado cuando aparece inminente la caída del autoritarismo, como ocurrió en Filipinas $y$, en menor medida en Haití. En el caso chileno, la política de la

"Ver "Comprehensive Strategy for Central America", declaración del Secretario de Estado Schultz ante el Comité de Relaciones Exteriores del Senado el 4 de agosto de 1983, Department of State Bulletin, septiembre de 1983, pp. 45-47.

xDcpartment of State Bulletin, marzo de 1983.

"Ver "Struggle for Democracy in Central America". Discurso del Secretario de Estado Schultz ante el World Affairs Council y la Cámara de Comercio de DaIlas el 15 de abril de 1983, Department of State Bulletin, mayo de 1983, pp. 1013; y "Central America; Defending Our Vital Interests", discurso del Presidente Reagan ante la sesión conjunta del Senado y la Cámara de Representantes el 27 de abril de 1983, Department of State Bulletin, junio de 1983. 
Administración Reagan cambió después de las protestas de 1983, variando desde el acercamiento inicial hacia la búsqueda de una salida política negociada ${ }^{27}$.

El cambio de énfasis de la protección de los derechos humanos a la promoción de la democracia, en todo caso, no ha significado el abandono de una activa preocupación por casos particulares de transgresiones de derechos humanos en diversos países. Sin embargo, la subordinación de la preocupación a los intereses estratégicos norteamericanos en varios casos ha tenido como efecto una crítica selectiva e incluso una atemuación práctica de la política de derechos humanos.

Los derechos humanos han continuado presentes en el debate político de Estados Unidos. El ex Secretario de Estado Cyrus Vance sostenía que "el concepto y la definición de los derechos humanos han sido deformados casi más allá de su reconocimiento" por la Administración Reagan ${ }^{28}$, volviendo a poner el tema en el debate de la agenda de una futura política exterior. Los efectos de la investigación Irán-contras sobre los términos de ese debate probablemente apuntarán a la búsqueda de una mayor consistencia entre los objetivos declarados y las políticas implementadas en el campo internacional. Ese debate tendrá espacio en la próxima campaña presidencial y en la acción más asertiva del Congreso durante los próximos meses. El control sobre la aplicación de la legislación existente y la recepción de los informes del Ejecutivo sobre la situación de los derechos humanos pueden ser un camino que dé resultados más inmediatos. La preocupación por los derechos humanos, que no sucumbió a las feroces críticas de 1980, seguramente volverá à manifestarse con más fuerza después de 1988.

${ }^{2 \top H}$ Heraldo Muñoz y Carlos Portales, Amistad Esquiva: Las Relaciones Estados Unidos-Chile, Editorial Pehuén, Santiago, 1987.

${ }^{28}$ Cyrus Vance, "The Human Rights Imperative", Foreign Policy, verano de 1986, p. 31. 